\title{
Flight on the Horizon: The Pivotal Year of 1896
}

\author{
F. E. C. Culick* \\ California Institute of Technology, Pasadena, California 91125
}

\begin{abstract}
It has not been customary to include early aeronautical history in the AIAA Annual Meeting. However, the special importance of this 100th anniversary justified the session, in which three papers were delivered. This brief introduction is intended to provide background and a context for those lectures, which will appear in subsequent issues of this journal.
\end{abstract}

$\mathbf{I}^{\mathrm{N}}$ $\mathrm{N}$ the stunning rush of inventions at the end of the 19th century, the year 1896 held events remarkably significant for the development of the airplane and aeronautics in the early part of the 20th century. The three major figures responsible for those pioneering aeronautical events were the German mechanical engineer Otto Lilienthal (1848-1896) and two Americans: Samuel P. Langley (1834-1906), a self-educated physicist and Secretary of the Smithsonian Institution, and Octave Chanute (1832-1910) an eminent civil engineer best known for his participation in development of the railway system in the midwest United States but in 1896 devoting his energies almost totally to invention of the flying machine. All three did much to solidify the foundations of early aeronautics by identifying, (occasionally unwittingly) and clarifying the problems to be solved. Their contributions were intimately tied to previous and contemporary activities in the quest to build a heavier-than-air flying machine. They learned from the past and their own progress helped make possible the later success of the Wright brothers.

So far as practical possibilities were concerned, in the mid-1890s prospects for building a piloted heavier-than-air powered aircraft were much better than were popularly perceived. Three major problems had essentially been solved: propulsion, structuraldesign, and basic aerodynamics. Propulsion had not presented a serious obstacle since the invention of the internal combustion engine. By 1902, sufficiently light engines could be constructed $(4 \mathrm{lb} / \mathrm{hp})$ that the use of inefficient propellers could have been tolerated in a practical machine. It was the Wright brothers who achieved a remarkable advance in propeller design, increasing the efficiency by a factor of about 1.4 or more. That improvement was crucial to their success in 1903 , for their engine weighed roughly $15 \mathrm{lb} / \mathrm{hp}$.

Since the early 1800 s, with the work of Sir George Cayley (17731857), correct practical ideas of structural design had been known. Simplified versions of kites, windmill blades, and boat designs were first used and were later improved by adapting some details of bridge designs. Lilienthal had extraordinary success with his wood, wire, and fabric construction of both monoplane and biplane gliders. Chanute improved upon Lilienthal's basic biplane design by adapting the Pratt configuration of a bridge truss.

Surprisingly little basic aerodynamics is required to devise a scheme for designing a glider. Cayley did so in 1804-1809 essentially by attaching horizontal and vertical tails to a kite. In 1849, a scaled-up version of his crude glider is reputed to have flown carrying a boy on at least one occasion; in 1853 a larger craft (Cayley called it the governable parachute) may have carried his coachman on a glide in a small valley. The story is possibly apocryphal in some of its details - the important indisputable fact is that Cayley first proposed that, unlike birds, a mechanicalflying machine should possess independentmeans of propulsionand generating lift. Moreover, he proposed the conventionalaircraft configuration as it is now known: vertical and horizontal aft tails and a wing possessing dihedral and using a curved airfoil. He had made measurements and knew that a cambered profile gave a lift/drag ratio superior to that

Received July 25, 1996; accepted for publication Oct. 20, 1996; also published in AIAA Journal on Disc, Volume 2, Number 2. Copyright 1996 by the American Institute of Aeronautics and Astronautics, Inc. AY rights reserved.

*Professor, Mechanical Engineering and Jet Propulsion, MC 205-45. Fellow AIAA. of a flat plate. With the two aft tails and dihedral, Cayley's aircraft was, at least in principle, stable about all three axes, although there is no firm evidence - indeed, it is highly unlikely - that Cayley really understood stability in the sense that we do now.

Lilienthal, Chanute, and Langley all followed Cayley's basic design and used the configuration of flying surfaces that is now conventional. Although they had an intuitive notion of stability, the three did not have an understanding of the true technical meaning of the term. Therefore, like all others attempting to build aircraft at the turn of the century, they could improve stability only by trial and error, and control necessarily became a crucial issue. The technical reason for general ignorance of the subject was that none of those trying to build aircraft wrote down an equation for moments and therefore had no theoretical framework for understanding stability.

Thus, the essential aeronautical problem that remained to be solved in the late 19th century was one of geometry: determine a configuration of surfaces, including controls, such that the known aerodynamic forces could be manipulated to provide equilibrium stability, and control. Cayley's configuration possessed equilibrium and probably stability. Although he proposed the use of pilot-operated controls, they were not used in flight. In any case, because no lightweight engines were available until much later, he was forced to abandon his project to construct a powered aircraft capable of carrying a human.

In 1871 Alfonse Pénaud (1850-1880) constructed and successfully flew a model with a wing span of 18 in. powered by twisted rubber bands driving a pusher propeller. The model had Cayley's conventional configuration; its flight of $131 \mathrm{ft}$ in the Tuileries Gardens in Paris on Aug. 18, 1871, was the first flight of a powered heavier-than-airmachine. In a paperpublished in 1872, P'enaud gave the first qualitativeexplanationof why the horizontalaft tail provides pitch stability in the face of small disturbances. P'enaud's success was well known by all who subsequentlytried to build aircraft large enough to carry a person, and all adopted the horizontal aft tail for intrinsic stability - except the Wright brothers, who concentrated on control exerted by the pilot. Their great achievement was realizing and demonstrating with a practicalaircraft that a skillful pilot could control, stabilize, and fly a machine that was unstable alone.

During the years after Penaud's death, there was considerable activity in developing flying machines in Europe and in the United States. Much of the effort, and faith, was devoted to lighter-thanair vehicles. Reflecting a common view of the situation in 1890 , upon being invited to join the British Aeronautical Society, Lord Kelvin responded "I have not the smallest molecule of faith in aerial navigation other than ballooning, or of expectation of good results from any of the trials we hear of, so you will understand that I would not care to be a member of the Aeronautical Society."

Lilienthal was the first aeronautical scientist/engineer having a technicaleducationand experience. Equally important to his accomplishments, he recognized a crucial matter of style: to build a successfulaircraft, he had simultaneously to learn how to fly. With that decision,Lilienthal was first to combine accepted notions of equilibrium and stability in flight with his new idea of control to maintain equilibrium in the face of disturbances. He became the first pilot, of hang gliders, and although killed while practicinghis philosophy, he inspired others by his example. He set the Wrights on their path to success and also motivated the rebirth of aviation in France in 1899 with the primitive gliding tests of Ferdinand Ferber (1847-1909). 
Less well known is the fact that Lilienthal also inspired a crucial step in the initial theory of airfoils. In his 1889 book, Lilienthal sketched his impression of streamlines for flow past a profile showing clearly his conclusion that for best performance (lift/drag) the flow departs the trailing edge smoothly. W. M. Kutta knew that result, believed it explicitly, and in 1902 introduced it as the theoretical constraint now known as the Kutta condition. Thus, Lilienthal contributed fundamentally to both the practice and theory of aircraft design.

ChanuterecognizedLilienthalas the contemporary leader in aeronautics. Whereas he vigorously pursued collecting all available information about flight, he also designed and constructed his own man-carrying gliders. Owing to his maturity in the 1890 s, Chanute was aided by others who actually flew the aircraft, with some limited success. Probably Chanute is most widely known for his encouragement of the Wrights from the beginning of their work and for their voluminous and detailed correspondence. His sole truly significant technical contribution was his adaptation of the Pratt truss bridge design as the basis for his biplane structure. That configuration was adopted by the Wright brothers and remained as the usual structural design of biplanes until cantilevered structures became known. Chanute's 1896 glider was his practical realization of contemporary understanding about constructing an aircraft.

Despite his extensive efforts to invent a successful airplane, Chanute was hampered by the notion that the machine must be intrinsically or automatically stable. He worked to progress beyond the hang glider, in which the pilot exercises control by shifting his center of mass, but always tried to reduce the operating responsibilities of the pilot. He did not investigate problems of control by deflecting surfaces and missed the hints given him by the Wright brothers concerning their use of wing warping to achieve control in roll. Chanute's eternal monument is his wonderful book Progress in Flying Machines, a collection of earlier articles, published in 1894. That volume summarizes essentially all of aeronautics and the practice of building aircraft in the $1890 \mathrm{~s}$.

Samuel P. Langley was already a highly respected internationally known astronomer in 1886 when his attention was drawn to the problems of flight by a lecture at the Buffalo meeting of the American Association for the Advancement of Science. As a physical scientist, Langley was impelled to investigate and solve what he perceived to be the fundamental problem of flight and aeronautics. He had considerable influence and financial resources, first as Director of the Allegheny Observatory in Pittsburgh and later (1887 until his death in 1906) as Director of the Smithsonian Institution.

As his object of fundamental aerodynamical research, Langley settled on the thin flat plate-possibly the worst choice from the point of view of providing information truly useful for designing an airplane. His work, begun in 1887, was published in a large historically interesting volume Experiments in Aerodynamics, published by the Smithsonian in 1891. Although uniquely extensive, the work had no apparent impact on practical or theoreticalaerodynamics.

Fortunately, quite distinct from his aerodynamic researches, Langley began designing and building a long series of models in 1887. In that program, he began directly with P'enaud's success. His relatively small, rubber-powered models were largely unsuccessful and he was never able to match P'enaud's flights of 1871

Believing that his chief difficulty lay in the weak thrust available with his twisted rubber, Langley took an enormous leap and determined to build large models powered by a light steam engine. At last, after 5 years of practically no success, in May 1896, Langley's steam-powered model no. 5 was launched from a houseboat and flew approximately two-thirds of a mile before touching down in the Potomac River. By any measure, that flight was a magnificent success. Not only was it the unquestioned first flight of a machine powered by an engine, but there is no record, except for Langley's own subsequent flights, that the feat has ever been duplicated. The model weighed about $30 \mathrm{lb}$ and had $14 \mathrm{ft}^{2}$ of wing area divided between two tandem wings. It is a machine and an accomplishment that even today's modelers must admire.

Langley had three successful flights with two large models in 1896, giving him sufficient confidence to scale up his tandem-wing design. The well-funded program produced two briefly publicized failures in 1903, probably causing more politicalthan technicaldamage to the field. In fact, his efforts in late 1903 generated a sense of urgency on the Wrights' part to get their powered airplane in the air as soon as they could.

Although he intended that his aeronautical researches should be based on sound physical principles and was widely known throughout his career, Langley had no important technical influence on the works of others. His most significant contribution to aeronautics was the example he set with his successful large models.

In the 1890 s, particularlyafter Lilienthal's death, no country could match the vigor of aeronautics in the United States. In addition to the activities of Chanute and Langley, and occasional frauds by a few less successful experimenters, there was a significant group in Boston. The Boston Aeronautical Society, founded by James Means (1853-1920), was composed largely of enthusiasticamateurs having considerably less technical experience than did Chanute and Langley. Among them was Albert C. Merrill, formerly a bank clerk, who eventually emigrated west. He became the first research assistant in aeronautics at the California Institute of Technology (Caltech), arriving in 1918. His primary technical responsibilitiesconsisted in designing, constructing, and operating a small wind tunnel (still in use at Caltech); he also served as instructor in accounting until his departure in the mid-1920s.

Like Chanute, but without personal commitment to constructing a full-scale aircraft, Means spent a great deal of time and effort popularizing the glowing prospects for aviation and encouragingothers. His greatest accomplishment was his Aeronautical Annual that appeared in three issues published between 1895 and 1897 . The journal contained articles by many of his contemporaries working in aeronautics and closely related fields, among them meteorology. In the 1896 issue, classic articles of aeronautical progress were reprinted, including Cayley's main works. When the Wrights first sought information about the state-of-the-artin aviation, they acquired copies of the Aeronautical Journal. On several occasions, they remarked on its importance to their own entry in the field.

In 1896, a Massachusetts Institute of Technology graduate student, Albert J. Wells, made the first quantitative measurements with a wind tunnel in the United States. Although it is likely that Wells at least knew of the Boston Aeronautical Society, there seems to be no documented connection. The wind tunnel had been invented in 1872 by Francis Wenham (1824-1906) in England but it had rarely been used. Only the airfoil data taken by Horatio Phillips (18451924) had any influence on aircraft design. Phillips's data were the basis for his 1884 and 1891 patents covering double-surfaceairfoils. Neither Lilienthal nor Langley used a wind tunnel but rather relied on measurements taken with a form of the whirling arm apparatus invented by Benjamin Robbins in the middle of the 18 th century.

Wells constructed his tunnel, which may have been the first since Phillips's tunnel, by directing the flow in a ventilation duct. His sole intention was to measure the drag on a flat plate oriented normal to the stream. Interpreted as Smeaton's coefficient, $k$ in the formula drag $=k(\text { speed })^{2}$, this quantity had become the reference example for drag data in the 19th century. Wells obtained values around 0.0045 , fairly close to the value of 0.0050 accepted at that time (drag is in pounds and speed is in miles per hour). In contrast, Langley found $k$ to be approximately 0.0030 , very close to the value known now for the same range of Reynolds number.

This matter is historically significant because the Wrights required Smeaton's coefficient to convert Lilienthal's data to the form they used in their design work. The incorrect value of $k$, approximately 0.0050 , recommended by Lilienthal led them seriously astray, the chief reason that they began their own program of windtunneltests. There seems to be no evidence that the Wrights knew of Wells's work - they learned of the wind tunnel from the writings of Wenham and Phillips in, among other places, Mean's Aeronautical Journal. Eventually, with clever merging of data taken in their wind tunnel and some results of full-scale tests of wings, the Wrights independently inferred the correct value and thereby improved their design procedure.

Even this brief historical perspective reveals 1896 as a pivotal year: Lilienthal died; Chanute reached the pinnacle of his success in constructing unpowered gliders; and Langley's extended flights of the first powered models gave him the confidence to scale up his tandem wing designand attempt piloted flights of a powered heavierthan-airmachine. Only Lilienthal's technicalaccomplishmentswere fundamentalto the successful invention of the airplane, but all three are significant figures in the evolution of aeronautics. 